\title{
Prediction of Perceived Stress of Hong Kong Nursing Students with Coping Behaviors over Clinical Practicum: A Cross-Sectional Study
}

\author{
Anson Tang Chui Yan \\ School of Nursing, Tung Wah College, Hong Kong, China \\ Email: ansontang@twc.edu.hk
}

How to cite this paper: Yan, A.T.C. (2019) Prediction of Perceived Stress of Hong Kong Nursing Students with Coping Behaviors over Clinical Practicum: A Cross-Sectional Study. Journal of Biosciences and Medicines, 7, 50-60.

https://doi.org/10.4236/jbm.2019.75008

Received: March 18, 2019

Accepted: May 14, 2019

Published: May 17, 2019

\begin{abstract}
Nursing students are facing more and more stress in their course of study especially in clinical practicum. The study aimed to predict nursing students' stress level in clinical practicum with coping behaviors. It was a retrospective cross-sectional study conducting in a self-financing institution in Hong Kong. Nursing students who were studying the pre-registration baccalaureate nursing program and completed all the practicum blocks were recruited. Those who had extended the study and failed any of the practicum blocks were excluded. Convenience sampling was used to recruit subjects. Participants were required to fill out the demographic sheet, COPE Inventory and Assessment of Stress among Nursing Students scale during lecture at the commencement of a semester. The whole data collection lasted for 30 minutes. Stepwise multiple regression was used to do the modeling with p-value being set at 0.05 . 131 eligible nursing students were recruited with about half of female students. The regression model accounted for $50 \%$ of the variance in the perceived stress level. Gender, focus on and venting of emotions, restraint, use of emotional social support and denial were positively associated with perceived stress level ( $\mathrm{R}$ squared $=0.52, \mathrm{p}=0.001$ ). It is to conclude that nurse educators can refer to the findings to screen out students with higher risk of being overwhelmed by clinical learning and ineffective coping. Proactive measures should be taken to prevent poor health outcomes.
\end{abstract}

\section{Keywords}

Perceived Stress, Nursing Students, Coping Behaviors, Clinical Practicum

\section{Introduction}

Nursing students persistently expressed feeling stressful to their study [1] [2]. 
Their stress level is significantly higher than students of other disciplines [3] [4]. Aside from academic stress, clinical practice is another major source of stress to nursing students [5] [6] [7] [8]. Previous studies found that students' stress level is determined by various intrinsic and extrinsic factors. Intrinsic factors refer to the demographic and personal characteristics such as gender, age, emotional intelligence, coping behaviors etc.; extrinsic factors are the conduciveness of the clinical environment, support from clinical personnel and nurse educators, preparation offered by training schools, etc. Stress can affect a person's physical and psychological health [9]. Poor physical and psychological health would compromise one's quality of work and learning ability [10] [11] [12]. Thus, early screening of nursing students with high stress in clinical learning is essential as nurse educators can intervene timely and appropriately to prevent poor health outcomes.

\section{Background}

Stress is a dynamic interplay between an individual and the surrounding [13]. The perceived stress of nursing students during clinical practicum was thoroughly documented. Nursing students by large experience moderate to high stress while they are having clinical practice [1] [2]. The major stressors are diverse but basically due to unknown situations, handling new technical equipment, heavy assignment and workload, difficulty in communicating with clinical staff and nurse educators, suffering of patients [1] [13] [14] [15]. The reported feelings of helplessness and difficulty in coping with the clinical learning process signified nurse educators the pressing need to review the effective coping among nursing students [16] [17]. Coping is an act to manage emotion by a person in order to decrease physical and psychological effects of stressful condition [18]. Sun et al. (2016)'s qualitative study found that nursing students used self-reflection in preparation for clinical practicum, finding ways to release emotions, distractions from the anxiety, and facing their difficulty head-on [17]. Other studies found that nursing students largely used transference, avoidance and problem-solving approaches to reduce stress [1] [2] [12] [14] [19].

Studies investigating the relationship between stress level and personal characteristics somewhat showed that one's stress level can be predicted by certain demographic and personal characteristics. It is understood that year of study was negatively correlated with the perceived stress level [2] [19]. Liu et al. (2015) reported that senior year students had lower stress level than junior students [5]. Hamaideh, Al-Omari and Al-Modallal (2016) found that reasons of choosing and nursing and whether having relatives in nursing field significantly affected students' perceived stress level [14]. Por et al. (2011) associated emotional intelligence with perceived stress. Its findings showed that students with higher emotional intelligence had a lower perceived stress $(p>0.05)$ [20].

A handful of studies investigated the relationship between coping behaviors and perceived stress of nursing students. Their findings indicate coping beha- 
viors may be able to predict students' stress level and health outcomes. Shikai, Shono and Kitamura (2009) found that emotion-focused approach could predict anxiety in nursing students [21]. Chan, So and Fong (2009) reported that senior students with higher level of perceived stress were more likely to choose problem-solving approach [2]. Labrague et al. (2018) examined stress level, sources of stress and coping behaviors among nursing students in Greece, The Philippines and Nigeria. Its result showed that perceived stress level was positively correlated with transference and avoidance approach; problem-solving approach was negatively correlated with the perceived stress level [19]. As such, the researchers aimed to use coping behaviors as predictors to predict the perceived stress level of nursing students. The corresponding hypothesis is there is an association between coping behaviors and perceived stress level of nursing students over clinical practicums. The findings will inform students and nurse educators the associated coping behaviors with students' stress level. It sheds light on which coping behaviors can predict students with high stress. Nurse educators can refer to this finding to screen out high risk students and provide timely interventions. Additionally, the findings might help nurse educators to design appropriate stress coping programs to promote constructive coping behaviors.

\section{Methods}

\subsection{Design \& Setting}

It was a retrospective cross-sectional study examining the relationship between the perceived stress level and coping behaviors in nursing students during clinical practicums. It was conducted in a self-financing tertiary institution in Hong Kong. Undergraduate nursing students were the target population.

\subsection{Participants}

Final-year nursing students who had completed all nursing practicums required by the pre-registration baccalaureate nursing program offered in the self-financing tertiary institution was the accessible group. It was estimated that there were about 300 students. Students who failed any of the practicum blocks or needed to extend the study period were excluded. To attain study power of 0.8 and medium effect size ( $f 2$ ) of 0.15 , the minimum sample size required was 139 for 15 predictors if alpha was set at 0.05 [22] [23].

\subsection{Measures}

Demographic information includes gender, age, program studied and clinical experiences other than the compulsory nursing practicums. Age was measured in continuous scale and the rest were in nominal scale.

Coping behaviors were measured by the COPE Inventory developed by Carver, Scheler and Weintraub (1989) [24]. It is a multidimensional coping inventory assessing people's responses towards stress. There are 60 items in the inventory measuring 15 coping behaviors: positive reinterpretation and growth, mental 
disengagement, active coping, use of instrumental social support, planning, suppression of competing activities, restraint, use of emotional social support, acceptance, humor, religious coping, focus on and venting of emotions, behavioral disengagement, denial and substance abuse. Each coping behavior is measured by four items. The respondents indicate the response on each item in a 4-point Likert scale. 1 means "I usually don't do that at all" and 4 means "I usually do this a lot". The summations of the scores gained by all four corresponding items are the score of the coping behavior. The score ranges from $4-16$. The higher the score, the more frequent the respondents used that coping behavior. Cronbach's alpha for the 15 coping behaviors ranged from 0.37 to 0.93 . Except for mental disengagement, the remainders of the alphas were all above 0.59 , with the majority above 0.70 . The average alpha was 0.79 [24].

The perceived stress level was measured by the Assessment of Stress in Nursing Students (ASNS) [25]. It is a 30-item questionnaire measuring six domains: performance of practical activities; professional communication; time management; environment; professional education and theoretical activities. The respondents rate each item in a 0 - 3 Likert scale. 0 means "did not experience any stress at the situation depicts in the item" and 3 means "high stress in the presented situation". The factor analysis confirmed that the conceptual model was acceptable. Sub-scores of the six domains are calculated by adding up ratings of corresponding items. Overall perceives stress level was measured by the aggregated scores of the 30 items. The score ranges from 0 - 90. The higher the score, the higher the perceived stress level. The Goodness of Fit Index was 0.91. The overall Cronbach's alpha was 0.89 . The internal consistency of the domains estimated by Cronbach's alpha ranged from 0.71 to 0.87 [25]. It was being selected in this study to operationalize the perceived stress level as it is specifically designed to measure nursing students in clinical practice.

\subsection{Data Collection}

The data collection was conducted in a lecture at the beginning of a semester. The researcher explained the procedure of the study and issued potential students information sheet and a set of questionnaires. A return of a complete set of questionnaires implied their agreement to participate into the study. The time required to fill out the questionnaire was about 30 minutes.

\subsection{Data Analysis}

SPSS version 23 was used to analyze the data. Descriptive statistics were reported to summarize the data. Mean and standard deviation were reported for continuous data; frequency and percentage were computed for nominal data. Independent t-test was run to examine the effect of gender, program studied and clinical experience other than the program requirement on the overall perceived stress level.

Multiple regression was used to investigate the relationship between the per- 
ceived stress level, behaviors and demographic variables significantly correlated with the perceived stress level. Stepwise approach was adopted to run the regression analysis. The final model only contained independent variables significantly associated with the perceived stress level. $\mathrm{P}$ value less than 0.05 was considered as statistically significant.

\subsection{Ethical Consideration}

Ethics approval was obtained from the ethics review committee of the self-financing tertiary institution. Information sheet and verbal explanation were given prior to the questionnaire administration to ensure the respondents fully understand the objective, procedure, potential benefits of the study as well as their own rights. It is anonymous. The complete questionnaires could only be accessed by the researcher and were kept in a locked cabinet in the researcher's office.

\section{Results}

Amongst the 139 returned questionnaires, eight of them were incomplete. Only 131 complete questionnaires were included in the statistical analysis. As shown in Table 1, there are $48.9 \%$ of male and $51.1 \%$ female students. Majority of them (77.1\%) were from the first-year entry of the pre-registration baccalaureate program and the rest $(22.9 \%)$ was from the senior year entry of the same program. $80 \%$ of the respondents did not have clinical experiences other than the program provided. Gender was found to have a significant effect on the stress level ( $\mathrm{p}=$ 0.001). Female students had a significantly higher stress level than male students in clinical practicum. Program studied and previous clinical experience had no significant effect on the stress level. Amongst the 15 coping behaviors, the top three being commonly employed by the respondents to relieve stress over practicum periods were positive reinterpretation and growth, use of instrumental social support and use of emotional social support.

Table 2 shows the perceived stress level of the respondents. The overall stress level of nursing students during the practicum periods was 49.0 (12.5). They reported having moderate level of stress in performance of practical activities, professional communication and professional education. They indicated a low stress level in time management, environment and theoretical activity.

Table 3 presents the regression analysis of the association between perceived stress level, coping behaviors and demographic data. The $\mathrm{R}$ value for regression was significantly different from $0, F(5,125)=78.52, p<0.001$. The overall model accounted for $52 \%$ pf the variance in the perceived stress intensity $\left(R^{2}=0.52\right)$. Adjusted $\mathrm{R}^{2}=0.50$, suggesting that $50 \%$ of the variance in the perceived stress level can be explained by focus on and venting of emotions (28.4\%), restraint (12.7\%), use of emotional social support (3.8\%), denial (4.2\%), and gender (2.5\%). The tolerance for the independent variables ranged from 0.653 to 0.916 , suggesting collinearity between the variables is unlikely [26]. The B coefficients 
Table 1. Descriptive statistics of demographic characteristics and coping strategies of nursing students $(\mathrm{N}=131)$.

\begin{tabular}{|c|c|c|c|}
\hline Items & Mean (SD) & Frequency $(\mathrm{N}, \%)$ & Stress intensity \\
\hline Age (years) & $23.1(1.1)$ & & \\
\hline \multicolumn{4}{|l|}{ Gender* } \\
\hline Male & --- & $64(48.9)$ & $45.5(11.4)$ \\
\hline Female & --- & $67(51.1)$ & $52.4(12.7)$ \\
\hline \multicolumn{4}{|l|}{ Programme } \\
\hline First Year Entry & --- & $101(77.1)$ & $49.2(12.2)$ \\
\hline Senior Year Entry & --- & $30(22.9)$ & $48.6(12.6)$ \\
\hline \multicolumn{4}{|l|}{$\begin{array}{l}\text { Clinical Experience other than the } \\
\text { Compulsory practicums }\end{array}$} \\
\hline Yes & --- & $110(84)$ & $48.9(11.8)$ \\
\hline No & --- & $21(16)$ & $49.3(15.8)$ \\
\hline \multicolumn{4}{|l|}{ Coping behaviors" } \\
\hline Use of instrumental social support & $10.5(2.3)$ & & \\
\hline Planning & $10.3(1.9)$ & & \\
\hline Active coping & $10.3(1.9)$ & & \\
\hline Suppression of competing activities & $10.0(1.9)$ & & \\
\hline Restraint & $9.2(1.9)$ & & \\
\hline Positive reinterpretation and growth & $11.2(1.8)$ & & \\
\hline Use of emotional social support & $10.5(2.7)$ & & \\
\hline Acceptance & $10.1(1.9)$ & & \\
\hline Humor & $7.9(2.5)$ & & \\
\hline Religious Coping & $7.8(3.9)$ & & \\
\hline Mental disengagement & $9.4(2.2)$ & & \\
\hline Focus on and venting of emotions & $9.1(2.5)$ & & \\
\hline Behavioral disengagement & $7.7(2.4)$ & & \\
\hline Denial & $7.2(2.4)$ & & \\
\hline Substance use & $5.8(2.6)$ & & \\
\hline
\end{tabular}

${ }^{*} \mathrm{p}<0.05 ;{ }^{*}$ Score range: $4-16$.

Table 2. Perceived Stress Intensity of Nursing Students at each ASNS Domain $(\mathrm{N}=131)$.

\begin{tabular}{ccc}
\hline Domain & Mean(SD) & $\begin{array}{c}\text { Corresponding Stress } \\
\text { Level }\end{array}$ \\
\hline Performance of practical Activities & $10.5(3.3)$ & Moderate \\
Professional Communications & $6.3(2.1)$ & Moderate \\
Time Management & $8.0(3.0)$ & Low \\
Environment & $4.7(3.1)$ & Low \\
Professional Education & $1.8(2.8)$ & Moderate \\
Theoretical Activity & $8.1(2.5)$ & Low \\
Overall stress level (range: $0-90)$ & $49.0(12.5)$ & --- \\
\hline
\end{tabular}


Table 3. The association of demographic characteristics and coping strategies with overall stress level $(\mathrm{N}=131)$.

\begin{tabular}{cccccc}
\hline \multirow{2}{*}{ Model $^{\mathrm{a}, \mathrm{b}}$} & \multicolumn{2}{c}{$\begin{array}{c}\text { Unstandardized } \\
\text { coefficients }\end{array}$} & $\begin{array}{c}\text { Standardized } \\
\text { coefficients }\end{array}$ & $\mathrm{t}$ & Sig.(p-value) \\
\cline { 2 - 4 } & \multicolumn{1}{c}{$B$} & Std. Error & $\beta$ & & \\
\hline $\begin{array}{c}\text { Focus on and venting } \\
\text { of emotions }\end{array}$ & 1.013 & 0.388 & 0.201 & 2.613 & $0.010^{*}$ \\
$\begin{array}{c}\text { Restraint } \\
\text { Use of emotional } \\
\text { social support }\end{array}$ & 1.750 & 0.501 & 0.260 & 3.494 & $0.001^{*}$ \\
Denial & 1.083 & 0.334 & 0.233 & 3.245 & $0.002^{*}$ \\
Gender & 1.328 & 0.385 & 0.258 & 3.449 & $0.001^{*}$ \\
\hline
\end{tabular}

${ }^{\mathrm{a}} \mathrm{R}^{2}=0.516$, adjusted $\mathrm{R}^{2}=0.496 ;{ }^{\mathrm{b}} \mathrm{DV}=$ Perceived stress intensity; ${ }^{\star} \mathrm{p}<0.05$.

showed that all five independent variables were significant predictors; $95 \%$ confidence intervals did not include 0 . The direction of the relationships suggested that students with the greatest stress are female and used more focus on and venting of emotions, restraint, emotional social support and denial to cope with their stress.

\section{Discussion}

The findings are congruent with previous studies that the stress level of nursing students was moderate. The main sources of stress came from performing practical activities, communicating with clinical personnel, and professional education which are also similar to those reported in other Asian studies [2] [6] but discrepant with others from western countries. Costa et al. (2014) reported that high stress level was found in time management and environment in nursing students who travelled by public transport and had work activity [27]. As the study was conducted in Sao Paulo which is totally different from Hong Kong in terms of socio-economic and geo-demographic conditions, it is no surprise that its finding is varied with the present study. Nurse educators need to be sensitive to nursing students' geographical locations in the future as Hong Kong now is part of the Greater Bay Area. The closer connection with cities within the Pearl River Delta implies that secondary school leavers from these cities may come to Hong Kong to study nursing. Their stressors may be different from students growing up in Hong Kong.

Same as other studies [2] [6] [8], emotion-focused approach was found to be more frequently used but not for the coping behaviors. In this study, positive reinterpretation and growth, and use of emotional social support were at the top three most frequently used coping behaviors. Yamashita et al. (2012) reported that acceptance and self-distraction were more frequently used [8]. Chan, So and Fong (2009) explored the coping behaviors of nursing students in Hong Kong, it reported that transference such as relaxation through watching TV, going to the movies, etc. was the most popular emotion-focused coping behavior among 
nursing students [2]. Regarding coping behaviors in problem-focused approach, use of instrumental social support was found commonly used in both the present study and Yamashita et al. (2012) [8]. The more frequent use of emotional and instrumental social support reflects that students nowadays are more willing to communicate their emotion with others and seek advice from people around as compared to ten years ago. Such change in students' coping behaviors may be explained by the swift growth of social media in the 21st century. In the era of technological explosion, people's mode of communication has been changed literally. They get used to communicate with people and share their daily life with others via social media such as Facebook, Twitter, WhatsApp etc. These communication platforms facilitate people to get in touch with each other and may also change the coping behaviors when people are facing stress.

The regression model suggested that none of the coping approaches is more favorable than the others to manage stress. It is necessary to identify the exact coping behaviors used by nursing students to identify students with higher risk of being overwhelmed by the stressful situation and ineffective coping. Restraint is the only coping behaviors in problem-focused approach that can predict stress level. Its positive association with perceived stress level signified nurse educators that not all problem-focused coping behaviors can effectively relieve stress. Restraint is a passive coping that one waits the right moment to act. The holding back of one's emotion without proper venting may intensify one's worries and fear to a situation, and so leads to higher stress level. In emotion-focused approach, positive reinterpretation and growth is used most but it is not a significant predictor to the stress level. Instead, use of emotional social support and focus on and venting of emotions were positively associated with the stress level. Their positive relationship with perceived stress level means that they are destructive to a stressful person. Both behaviors attempt to relieve one's stress by venting emotion either via seeking sympathy from someone or expressing one's feelings. Since the use of emotional social support is the third frequently used coping behavior, nurse educator shall educate students these destructive coping behaviors and facilitate students to adopt other more constructive coping behaviors.

There are some limitations in this study. First, it is not easy to compare the results with other studies as the instruments used to measure the perceived stress level in other studies were not the same as the present study. The authors adopted this instrument because it is specifically designed to assess the stress level of nursing students in clinical practicum. Second, this study only recruited subjects from one nursing program in Hong Kong, the varied duration and pattern of clinical practicums in other programs and other extrinsic factors such as geographic, socio-economic and cultural difference were not considered in the present study. It therefore limits the generalizability of the findings. Third, the study excluded students who had failed clinical practicums and extended their study period due to slow study pace. The results cannot apply to slow learning students. It is believed slow learners may experience even higher stress in clinical 
learning, their stress level and coping behaviors should not be ignored by nurse educators.

\section{Conclusion}

It shed light on the impact of different coping behaviors on nursing students' stress level. The significantly positive association of focus on and venting of emotion, denial, use of emotional social support and restraint coping with the perceived stress level provides insight to nurse educators that female students with these coping behaviors are more likely to experience high stress. Proactive measures should be taken to prevent intensification of stress level due to the use of inappropriate coping behaviors. The authors also recommended that future studies should widen the sampling pools to recruit nursing students from different nursing programs and cities to increase the generalizability of the results.

\section{Acknowledgements}

The author expresses enormous thanks to students who helped to prepare the materials needed, recruit participants and collect data. She also thanks students who are willing to participate in the study and Tung Wah College who supported the study.

\section{Conflicts of Interest}

The authors declare no conflicts of interest regarding the publication of this paper.

\section{References}

[1] Labrague, L.J., McEnroe-Petitte, D.M., Thomas, L., Papathanasiou, J.V. and Tsaras, K. (2016) A Literature Review on Stress and Coping Strategies in Nursing Students. Journal of Mental Health, 26. https://doi.org/10.1080/09638237.2016.1244721

[2] Chan, C.K.L., So, W.K.W. and Fong, D.Y.T. (2009) Stress and Their Coping Strategies in Clinical Practice. Journal of Professional Nursing, 25, 307-313. https://doi.org/10.1016/j.profnurs.2009.01.018

[3] Goff, A. (2011) Stressors, Academic Performance and Learned Resourcefulness in Baccalaureate Nursing Students. International Journal of Nursing Education Scholarship, 8, 1-20. https://doi.org/10.2202/1548-923X.2114

[4] Shaban, I.A., Khater, W.A. and Akhu-Zaheya, L.M. (2012) Undergraduate Nursing Students' Stress Sources and Coping Behaviors during Their Initial Period of Clinical Training: A Jordanian Perspective. Nurse Education in Practice, 12, 204-209. https://doi.org/10.1016/j.nepr.2012.01.005

[5] Liu, M., Gu, K., Wong, T.K.S., Luo, M.Z. and Chan, M.Y. (2015) Perceived Stress among Macao Nursing Students in the Clinical Learning Environment. International Journal of Nursing Sciences, 2, 128-133. https://doi.org/10.1016/j.ijnss.2015.04.013

[6] Chen, Y.W. and Hung, C.H. (2014) Predictors of Taiwanese Baccalaureate Nursing Students' Physio-Psycho-Social Responses during Clinical Practicum. Nurse Education Today, 34, 73-77. https://doi.org/10.1016/j.nedt.2013.02.021 
[7] Gorostidi, X.Z., Egilegor, X.H., Erice, M.J., Iturriotz, M.J., Garate, I.E., Lasa, M.B. and Cascante, X.S. (2007) Stress Sources in Nursing Practice; Evolution during Nursing Training. Nurse Education Today, 27, 777-787. https://doi.org/10.1016/j.nedt.2006.10.017

[8] Yamashita, K., Saito, M. and Takao, T. (2012) Stress and Coping Styles in Japanese Nursing Students. International Journal of Nursing Practice, 18, 489-496. https://doi.org/10.1111/j.1440-172X.2012.02056.x

[9] Silver, H.K. and Glicken, A.D. (1990) Medical Student Abuse. Incidence, Severity, and Significance. JAMA, 31, 103-122. https://doi.org/10.1001/jama.263.4.527

[10] Choi, G.Y. (2009) The Relationship between Perceptions of Nursing College Students Regarding Clinical Practice Environment and Related Variables. Korean Journal of Adult Nursing, 21, 129-139.

[11] Elkin, A.J. and Rosch, P.J. (1990) Promoting Mental Health at the Workplace: The Prevention Side of Stress Management. Occupational Medicine: State of the Art Review, 5, 739-754.

[12] Lo, R. (2002) A Longitudinal Study of The Perceived Levels of Stress, Coping and Self-Esteem of Undergraduate Nursing Students: An Australian Case Study. Journal of Advanced Nursing, 39, 119-126. https://doi.org/10.1046/j.1365-2648.2000.02251.x

[13] Pulido-Martos, M., Augusto-Landa, J.M. and Lopez-Zafra, E. (2011) Sources of Stress in Nursing Students: A Systematic Review of Quantitative Studies. International Nursing Review, 59, 15-25. https://doi.org/10.1111/j.1466-7657.2011.00939.x

[14] Hamaideh, S.H., Al-Omari, H. and Al-Modallal, H. (2016) Nursing Students' Perceived Stress and Coping Behaviors in Clinical Training in Saudi Arabia. Journal of Mental Health, 26, 1-7. https://doi.org/10.3109/09638237.2016.1139067

[15] Burnard, P., Edwards, D., Bennett, K., Thaibah, H., Tothova, V., Baldacchino, D., et al. (2008) A Comparative, Longitudinal Study of Stress in Student Nurses in Five Countries: Albania, Brunei, the Czech Republic, Malta, and Wales. Nurse Education Today, 28, 134-145. https://doi.org/10.1016/j.nedt.2007.04.002

[16] Shipton, S.P. (2002) The Process of Seeking Stress Care: Coping as Experienced by Senior Baccalaureate Nursing Students in Response to Appraised Clinical Stress. Journal of Nursing Education, 41, 243-256.

[17] Sun, F.K., Long, A., Tseng, Y.S., Huang, H.M., You, J.H. and Chiang, C.Y. (2016) Undergraduate Student Nurses' Lived Experiences of Anxiety during Their First Clinical Practicum: A Phenomenological Study. Nurse Education Today, 37, 21-26. https://doi.org/10.1016/j.nedt.2015.11.001

[18] Largo-Wight, E., Peterson, P.M. and Chen, W.W. (2005) Perceived Problem Solving, Stress, and Health among College Students. American Journal of Health Behavior, 29, 360-370. https://doi.org/10.5993/AJHB.29.4.8

[19] Labrague, L.J., McEnroe-Petitte, D.M., Papathanasiou, J.V., Edet, O.B., Tsaras, K., Leocadio, M.C., Colet, P., Kleisiaris, C.F., Fradelos, E.C., Rosales, R.A., Santos-Lucas, K.V. and Velacaria, I.T. (2018) Stress and Coping Strategies among Nursing Students: An International Study. Journal of Mental Health, 27, 402-408. https://doi.org/10.1080/09638237.2017.1417552

[20] Por, J., Barriball, L., Fitzpatrick, J. and Roberts, J. (2011) Emotional Intelligence: Its Relationship to Stress, Coping, Well-Being and Professional Performance in Nursing Students. Nurse Education Today, 31, 855-860. https://doi.org/10.1016/j.nedt.2010.12.023

[21] Shikai, N., Shono, M. and Kitamura, T. (2009) Effects of Coping Styles and Stressful 
Life Events on Depression and Anxiety in Japanese Nursing Students: A Longitudinal Study. International Journal of Nursing Practice, 15, 198-204.

https://doi.org/10.1111/j.1440-172X.2009.01745.x

[22] Field, A. (2013) Discovering Statistics Using IBM SPSS Statistics. 4th Edition, Sage, London, United Kingdom.

[23] Stevens, J. (1992) Applied Multivariate Statistics for the Social Sciences. 2nd Edition, Erlbaum, Hillsdale, New Jersey.

[24] Carver, C.S., Scheler, M.F. and Weintraub, J.K. (1989) Assessing Coping Strategies: A Theoretically Based Approach. Journal of Personality and Social Psychology, 56, 267-283. https://doi.org/10.1037/0022-3514.56.2.267

[25] Costa, A.L.S. and Polak, C. (2009) Construction and Validation of an Instrument for the Assessment of Stress among Nursing Students. Revista da Escola de Enfermagem da USP.

[26] Bryman, A. and Cramer, D. (1997) Quantitative Data Analysis with SPSS for Windows. Routledge, London.

[27] Costa, A.L.S., Guido, L.D.A., Silva, R.M.D., Lopes, L.F.D. and Mussi, F.C. (2014) Stress Intensity of Nursing Students Regarding Biosocial and Academic Characteristics: A Cross-Sectional Study. Journal of Nursing Education and Practice, 4, 29-37. https://doi.org/10.5430/jnep.v4n2p29 